\title{
Desejo de desejo na mercadoria e o olhar do artista $^{1}$
}

Luciene Jung de Campos (PPGTUR/UCS)

\section{Resumo}

O presente artigo é uma tentativa de fazer uma leitura provisória da sociedade contemporânea e da condição de resistência do sujeito. Trata do sujeito e da mercadoria capturados pela publicidade/propaganda, onde o artista faz a denúncia. Busca uma aproximação entre os campos da arte, da psicanálise e da análise do discurso. Propõe uma discussão através do esquema L de Lacan para pensar a relação imaginária do sujeito com a publicidade.

Palavras-chave: Imagem; Resistência; Sujeito.

\footnotetext{
1 Este artigo é um recorte da minha tese de doutoramento Imagens à Deriva: Interlocuções entre a arte, psicanálise e a análise do discurso, sob orientação da Profa. Dra. Maria Cristina Leandro Ferreira.
} 
“O espetáculo é o momento em que a mercadoria ocupou totalmente a vida social", refere Guy Debord (1997, p. 30) em seu livro A sociedade do espetáculo. Com a revolução industrial, a divisão do trabalho e a produção em massa para o mercado mundial, a mercadoria aparece como uma das principais forças que orienta a vida social. O espaço social é invadido pelo excedente de mercadorias e o consumir passa a ser tão obrigatório quanto o produzir, diz o autor "o consumo alienado torna-se para as massas um dever suplementar à produção alienada" (DEBORD, 1997, p. 31). Assim, o proletário deixa de ser visto apenas como o operário que deve receber o mínimo para a garantia de sua sobrevivência, obrigando-se a vender contínua e incessantemente a sua força de trabalho. E passa a existir fazendo parte da massa de consumidores, cuja obrigação é regular o estoque de mercadorias em abundância. Em páginas anteriores, deste mesmo livro, ele conceitua espetáculo: "o espetáculo não é um conjunto de imagens, mas uma relação social entre pessoas, mediada por imagens" (DEBORD, 1997, p. 14). Para abordar discursivamente a espetacularização da imagem mediadora das relações na sociedade de consumo, apresento algumas obras do ensaio fotográfico Outdoor's São Paulo, Um Retrato Urbano, de Carlos Goldgrub, realizado entre 2002 e 2004. O artista utiliza uma câmera Nikon F4, filme Tri-X, e apenas uma lente zoom 80-200mm: "Esse equipamento me permitiu mais aproximação e também a possibilidade de cortes no momento do enquadramento, obtendo assim uma imagem final mais limpa", refere Goldgrub (2012, p. 5). Os anúncios interpelam os passantes nas ruas no formato de gigantescos painéis, conforme flagrou o fotógrafo:

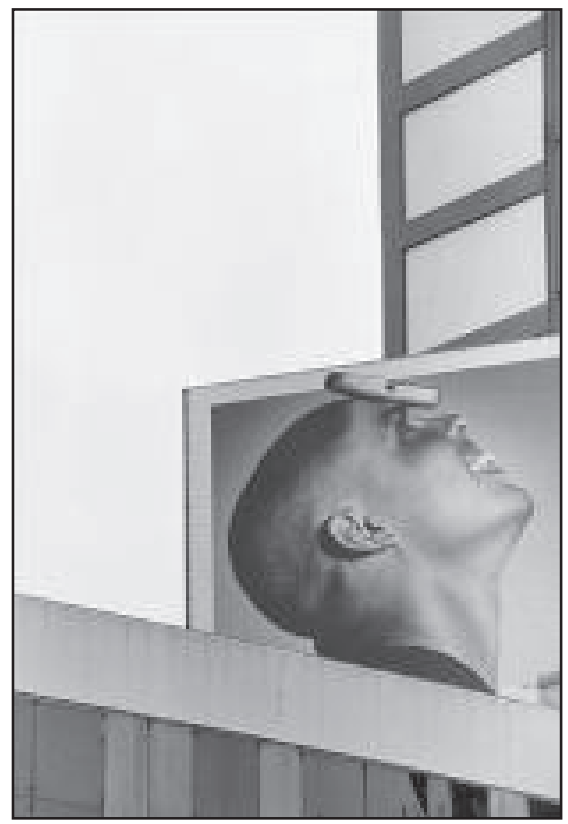

Fig. 1 - Carlos Goldgrub, Série Outdoor's, 2004 
Na imagem acima (Fig.1), o personagem é bem conhecido, trata-se de um famoso jogador de futebol. O jogo metafórico da publicidade/propaganda é registrado pelo artista, onde um elemento é substituído por outro: a bola é substituída por um telefone celular e o jogador talentoso é substituído pelo garoto-propaganda. É a imagem pessoal que parece se converter em mercadoria. A exploração estética da cabeça raspada remete ao formato da bola, a uma cabeça-globo que equilibra um celular. A sua habilidade desportiva passa para segundo plano e o que fica em evidência são os contratos milionários que tornam ilimitada a sua capacidade de consumo. A escalada social parece ser explorada pelo artista no ângulo em que ele ajusta a fotografia, aproveitando os patamares ascendentes da arquitetura. Contra o fundo branco a imagem expõe o perfil em degraus que finalizam em uma escada sem fim.

O garoto-propaganda propõe o consumo fácil com um sorriso no rosto, relembra a felicidade prometida na cultura do efêmero pela aquisição de mercadorias, apelo recorrente na publicidade/propaganda. Trata-se do sujeito "livre e competente" da formação discursiva esportiva que migra das camadas sociais mais desfavorecidas para o topo da pirâmide em função de seu talento. A imagem de Goldgrub reapresenta o sintoma: disfarça a exploração do atleta enquanto trabalhador e evidencia um gozo.

Em plena cultura da performance e da liberdade individual "vive-se uma espécie de mais-alienação", como refere Kehl "de rendição ao brilho da imagem de algumas personagens públicas identificadas ao gozo que os objetos deveriam proporcionar" (BUCCI; KEHL, 2004, p. 65). Maria Rita Kehl propõe um diálogo com a obra de Debord em seu texto $O$ espetáculo como meio de subjetivação, onde defende que a imagem industrial, nesse caso, tem a qualidade do fetiche, e sintetiza o modo contemporâneo de alienação que chama de "mais-alienação" para conceituar a expropriação simbólica análoga ao resultado da mais-valia (BUCCI; KEHL, 2004, p. 49).

Lacan (1998), no texto O estádio do espelho, trata da eficácia da imagem para produzir a identificação primordial com o Outro antes que a linguagem lhe institua sua função de sujeito. Dependência inicial e total do olhar do Outro, onde se organiza uma matriz simbólica que daria suporte às identificações secundárias. Pêcheux inspira-se nesta abordagem para elaborar o conceito de formações imaginárias na teoria do discurso.

Prosseguindo o diálogo entre a Psicanálise e a Análise do Discurso, atribuo à matriz simbólica o locus para inscrição da ideologia. Nesta linha, busco refletir sobre a ideologia enquanto o "espelho" que cumpre a tarefa de organizar a imagem fragmentada do sujeito dividido e desamparado. Organização essa, imaginária, com a qual o sujeito se identifica pelo mecanismo de projeção. Penso que o esquema L proposto por Lacan pode ajudar a elucidar a constituição do sujeito via o espelhamento no olhar do 
Outro. No caso, o Outro é a publicidade/propaganda, enquanto imagem da mercadoria, na qual o sujeito se projeta e se identifica.

O "esquema L" é considerado o esquema da dialética intersubjetiva que evidencia a relação dual do eu com sua projeção $\left(a^{\prime}\right)$, esta projeção confunde-se com a imagem de si mesmo e a do outro. A estrutura busca encenar a relação imaginária de simetria e reciprocidade que implica a reduplicação de seus termos: o pequeno outro (a) é exponenciado como grande Outro (A), onde a posição do terceiro implica a do quarto (S):

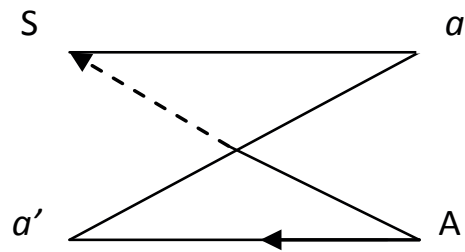

Fig. 2 - Esquema L de Lacan

O estado do sujeito $S$ (neurose ou psicose) depende do que se desenrola no Outro A. O que nele se desenrola articula-se como um discurso (o inconsciente é o discurso do Outro), do qual Freud procurou definir a sintaxe relativa aos fragmentos que nos chegam em momentos privilegiados como os sonhos, os lapsos e os chistes. Nesse discurso, o sujeito (S) é repuxado para os quatro cantos do esquema, como diz Lacan: em sua inefável e estúpida existência, para $a$, seus objetos, $a^{\prime}$, seu eu, que é o que se reflete de sua forma na relação imaginária com seus objetos, e A, lugar de onde lhe pode ser formulada a questão de sua existência (Lacan, 1998, p. 555). Abaixo, um esquema para apresentar a relação imaginária do consumidor (S) com a publicidade/propaganda (PP):

Quem sou eu?

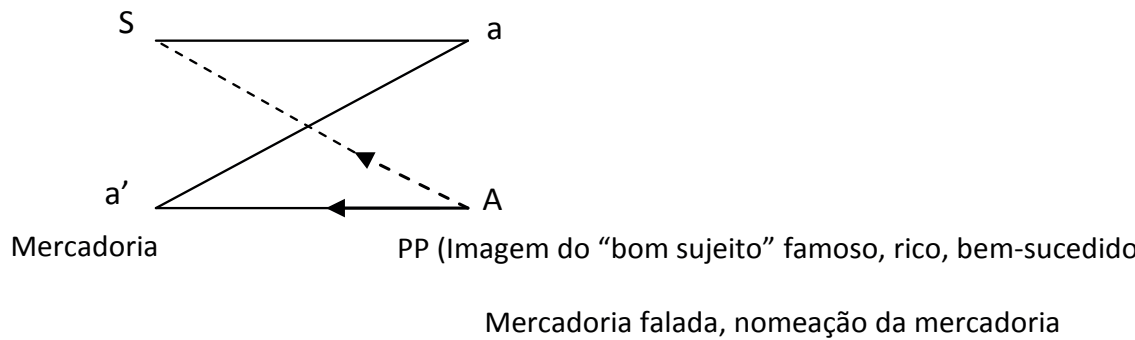

Fig. 3 - A relação imaginária do consumidor com a Publicidade/Propaganda (PP) (Adaptado do esquema L de Lacan) Fonte: Campos, 2010

No esquema acima (Fig.3), a Publicidade/Propaganda está no lugar do grande Outro (A), enquanto imagem e discurso sobre a mercadoria. A mercadoria é o objeto da publicidade/propaganda (PP). A publicidade dirige-se ao grande público nomeando os 
atributos, funções e resultados da mercadoria, que é o seu objeto $\left(a^{\prime}\right)$. Ao mesmo tempo em que a publicidade/propaganda nomeia a mercadoria, ela também nomeia o sujeito. $O$ sujeito deseja a mercadoria na esperança de que ela diga quem ele é, assim como, a publicidade/ propaganda (PP) diz o que é a mercadoria. Nesse caso, poder-se-ia dizer que é a imagem que assume o lugar de fetiche e não mais a mercadoria, onde a publicidade/propaganda sustenta as relações de dominação e exploração negadas na sociedade de consumo.

Bucci e Kehl (2004) defendem a ideia de que as sociedades contemporâneas, as sociedades do espetáculo tiveram que fazer um retorno para os corpos humanos e que a lógica do fetichismo da mercadoria deslocou-se para o território de circulação das imagens, associando alguns seres humanos "especiais", "escolhidos" a mercadorias:

Diferentemente do caso das mercadorias, que só servem de suporte para a mistificação dos homens que as trocam, os vendedores, os vendedores de imagens são presas da própria ilusão que produzem. São, ao mesmo tempo, o fetiche e o fetichista, o ilusionista e o iludido (BUCCI; KEHL, 2004, p. 82).

Para trabalhar essas questões é preciso rever os conceitos de fetiche e de sintoma. Por sinal, são dois conceitos em confluência na psicanálise e no materialismo histórico.

\section{O sintoma: uma metáfora da história}

Se Freud assumiu a responsabilidade - ao contrário de Hesíodo, para quem as doenças enviadas por Zeus avançavam para os homens em silêncio - de nos mostrar que existem doenças que falam, e de nos fazer ouvir a verdade do que elas dizem, parece que essa verdade, à medida que sua relação com um momento da história e com uma crise das instituições nos aparece mais claramente [...] (LACAN, 1998b, p. 216).

Lacan faz lembrar, na citação acima, como Freud iniciou sua investigação pelo sintoma, tratando as histéricas, cujo sintoma denunciava o estado daquelas mulheres que não podiam se expressar na sociedade conservadora e autoritária da época. Tratava-se do sujeito inibido histórica e culturalmente determinado. Cujos sintomas estavam vinculados à impossibilidade de renunciar ao objeto primário e encontrar outra forma de existência. Por conta disso, a "doença" parece estar ligada a essa impossibilidade de renúncia a esse desejo originário. Esta demanda provoca inibição e angústia no ser humano enquanto um animal alijado da natureza, que perdeu o instinto e com isso foi jogado na incerteza e no conflito, enquanto falasseres que somos.

Lacan constrói o esquema L do caso Dora, um dos casos clássicos de histeria, trabalhado por Freud e relido por Lacan no Seminário IV: Relação de objeto: 
O que é uma mulher?

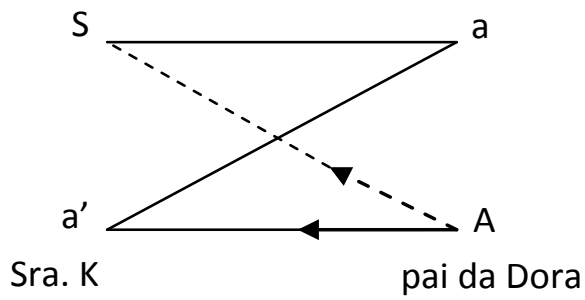

Fig. 4 - O esquema L do caso Dora, segundo Lacan

O esquema L é uma topologia onde o sujeito (S) se estende entre $a$ e $a^{\prime}$, num "véu de miragem narcísica" que serve para sustentar tudo o que nela venha se refletir por seus efeitos de sedução e captura (LACAN, 1998, p. 557). O desejo da histérica é o desejo de desejo, cujo desejo é o desejo do Outro. A histérica trata de se colocar na posição de substituir o Outro (o pai) nesta função do desejo: ela esvazia sua relação com o objeto (Sra. K), fomentando o desejo do Outro por este objeto. Ela se empenha em sustentar o amor deste outro (Sra. K) que é seu verdadeiro objeto - situação bastante ambígua, Dora sustenta o desejo de seu pai pela Sra. K e mascara seu objeto que é a Sra. K., portadora de sua questão: $O$ que é uma mulher?

Na clínica médica, o sintoma está ligado à doença e é sempre patológico; para a psicanálise, ele é o início da cura e indica a presença do sujeito do inconsciente. O sintoma para a psicanálise não diz respeito a uma doença orgânica, mas a uma formação do inconsciente. A psicanálise por sua vez, tem sua origem na clínica médica, porém no momento em que se diferencia como outro campo de saber, ela rompe com essa clínica. E o sintoma é sintoma desta divergência.

Foucault (2006), em O nascimento da clínica, descreve o sintoma como a primeira transcrição da doença, na sua condição de inacessibilidade. Para Foucault, o sintoma é uma linguagem que torna visível o invisível da doença. O sintoma para o médico é signo, que representa o significado de uma doença. Para o psicanalista e para o analista do discurso o sintoma é significante.

Freud, em Inibição, sintoma e angústia (1925) explica o processo de produção do sintoma:

Um sintoma surge de um impulso que foi afetado pelo recalque. Se o ego, fazendo uso do sinal de desprazer, atingiu seu objetivo de suprimir inteiramente o impulso, nada saberemos como isso aconteceu. Podemos apenas descobrir algo a esse respeito pelos casos nos quais o recalque em maior ou menor grau, tenha falhado. Nesse caso, a posição é que o impulso encontrou um substituto apesar do recalcamento, mas um substituto muito mais reduzido, deslocado e inibido, e que não é mais reconhecido como uma satisfação. E quando o impulso substitutivo é levado a efeito, não há qualquer sensação de 
prazer; sua realização apresenta, ao contrário, a qualidade de uma compulsão (FREUD, 1976, p. 116).

Nesta citação, aparece a ideia do sintoma enquanto um compromisso. Compromisso entre o desejo e a defesa contra esse desejo. No entanto, é um contrato que não é bem cumprido, ele tem uma falha. Trata-se do retorno do recalcado que insiste: o impulso encontrou um modo de se fazer presente de forma deslocada e minimizada. A defesa falhou, mas é vigorosa, pois consegue reduzir um processo de satisfação a uma compulsão que se consome no próprio sujeito, garantindo a inibição do desejo.

Penso ser pertinente discutir uma das imagens da série Outdoor's, onde aparece uma cadeia de significantes que nos ajudaria a pensar esta questão. $\mathrm{O}$ artista posiciona a sua câmera de modo que seja possível visualizar o outdoor que veicula a imagem de um casal em cena íntima, superpondo-se ao pé da imagem, um cartaz de preços de combustíveis (gasolina comum $\mathrm{R} \$ 1,59$ e álcool $\mathrm{R} \$ 0,68)$. Ele promove um deslizamento de significantes:

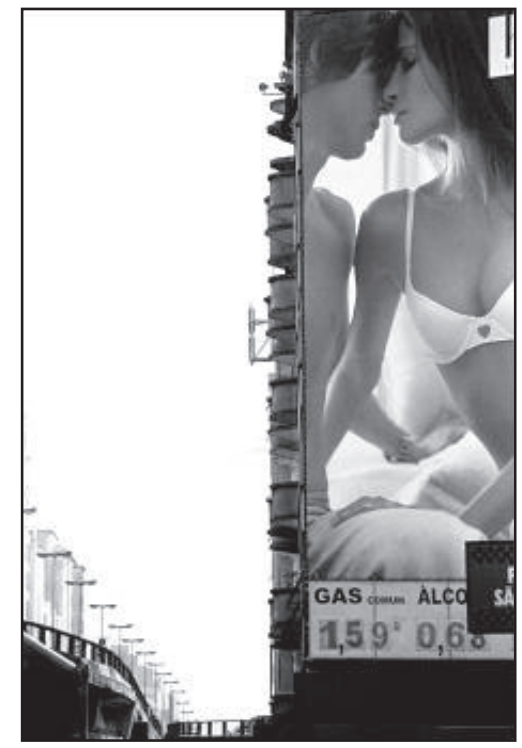

Fig. 5 - Carlos Goldgrub, Série Outdoor's, 2004

GAS comum ÁLCO[ol] $\rightarrow$ Combustível $\leftrightarrow$ energia $\leftrightarrow$ desejo $\rightarrow$ preço $=$ mercadoria

A expressão "GAS comum" e a imagem do casal condensa a ideia de combustível/ desejo. A atração sexual e amor são afetos, relações de intensidades e trocas. A energia está sendo comercializada no anúncio, o que vale para o combustível e para os corpos aos quais os preços estão afixados. O desejo é mercadoria. A imagem é perturbadora, ela lida com o vácuo, ocupando metade do espaço, com o indicativo monetário sobreposto ao casal, sugerindo precificação humana. A imagem estaria apontando para um jogo e para a mercantilização das relações? Para a impossibilidade de desejar, quando o desejo adquire o status de 
mercadoria? Para o abandono de Eros? Não temos as respostas, apenas a obra perturbadora.

Lacan (1998), em Escritos, no seu texto Do sujeito enfim em questão, aborda uma dimensão do sintoma que é a do retorno de uma verdade que vem perturbar a "boa ordem". Nesse sentido, ele reconhece na crítica de Marx ao capitalismo, os artifícios ridiculamente travestidos da razão no retorno materialista da verdade que assume forma e corpo na mais-valia. Não se trata do status de signo, de representação, mas da apresentação de algo que retorna, como registrou Freud. Lacan conclui que o sintoma só pode ser lido na ordem do significante, não do significado. $\mathrm{O}$ significante só tem sentido na sua relação com outro significante e é nessa articulação que reside a verdade do sintoma:

O sintoma tinha um ar impreciso de representar alguma irrupção da verdade. A rigor, ele é verdade, por ser talhado na mesma madeira que ela é feita, se afirmarmos materialisticamente que a verdade é aquilo que se instaura a partir da cadeia de significante (LACAN, 1998, p. 235).

Sob este aspecto, a indagação de Zizek é pertinente: “Como foi possível que Marx, em sua análise do mundo das mercadorias, produzisse uma noção que também se aplica à análise dos sonhos, aos fenômenos histéricos e assim por diante?" (ZIZEK, 1999, p. 297).

Ele mesmo conclui que ambos, Marx e Freud, evitaram o fascínio pelo "conteúdo" e se preocuparam com a forma: como os pensamentos adquiriram essa forma no sonho? Por que o trabalho humano só consegue se afirmar na forma-mercadoria? O que passou interessar para Freud eram os mecanismos de deslocamento e condensação que trabalham a forma do sonho (na elaboração do conteúdo manifesto que é apresentado). O importante não é só "descobrir" o conteúdo latente, mas reconhecer o que se produziu neste intervalo entre o latente e o manifesto.

Freud busca explicar esse fenômeno. Preocupa-se em superar a ideia de que o sonho é uma confusão sem sentido, simples interferência de processos fisiológicos. Inicialmente, é preciso dar um passo em direção à abordagem hermenêutica e admitir que o sonho veicula uma mensagem encoberta que necessita ser revelada através de um método interpretativo. Depois, é preciso abandonar esse centro de significação de sentido oculto e profundo do sonho e buscar o processo ao qual esses pensamentos oníricos latentes foram submetidos e indagar-se sobre o seu funcionamento.

\section{O segredo da forma-mercadoria}

Zizek (1999) compara os esforços de Freud com os de Marx, na análise do "segredo da forma-mercadoria", onde ele faz uma articulação semelhante, em dois tempos. Primeiro devemos descartar a aparência de que o valor estipulado para uma mercadoria é um mero acaso, simples consequência da lei de oferta e procura. 
Em seguida, é preciso admitir o "sentido oculto" por trás da forma-mercadoria, o que expressa essa forma; devemos penetrar no "enigma" do valor das mercadorias. No entanto, a determinação da grandeza do valor da mercadoria pelo tempo de trabalho é um segredo que se esconde nas flutuações de valores dessas mercadorias e mesmo que descoberto, isso não alteraria o modo como se dá essa determinação. O desmascaramento do segredo, portanto, não basta: é a exploração do trabalho a verdadeira fonte de riqueza. Não se trata do segredo por trás da forma, mas da própria forma como essa economia política clássica funciona. Então o segredo da magnitude do valor da mercadoria continua sendo um mistério indecifrável, da mesma forma que o conteúdo latente do sonho.

Mas, o que interessa nos dois casos é como o sentido latente se disfarçou desta maneira. "Por que o produto do trabalho tem seu valor alterado assim que assume a forma de mercadoria? É a questão que a economia política não pode se colocar e que está vinculada à sua própria presença" (ZIZEK,1999, p. 300).

Trata-se, então, de uma Outra Cena que está em jogo, como alertou Freud, externa ao pensamento face à qual a forma do pensamento já está articulada de antemão. A ordem simbólica é uma ordem formal que completa ou que rompe a relação dual da relação factual "externa" (a troca de mercadorias) com a experiência subjetiva "interna" (a ilusão fetichista no ato da troca da mercadoria). Assim, chegamos à dimensão do sintoma na sua semelhança com o ideológico: uma formação cuja força implica um certo não-conhecimento por parte do sujeito. O sujeito só pode sustentar o seu sintoma na medida em que sua lógica lhe escapa.

Por exemplo, no capitalismo, o uso do ideário setecentista de liberdade e igualdade é falso. A liberdade específica de o trabalhador vender "livremente" sua força de trabalho no mercado subverte essa noção universal de liberdade. $\mathrm{O}$ mesmo também se pode demonstrar quanto à justa troca de equivalentes, esse ideal de mercado. A força de trabalho passa a ser uma mercadoria para os trabalhadores que não são donos dos meios de produção e que, por conseguinte, são obrigados a vender no mercado seu próprio trabalho, ao invés de produtos.

Com essa nova mercadoria - a força de trabalho - a troca de equivalentes anula-se na apropriação da mais-valia que materializa a nova forma de exploração do capital. O ponto decisivo aqui é essa negação que é própria à troca de equivalentes e não sua simples violação: a força de trabalho não é "explorada" no sentido de seu pleno valor não ser remunerado; em princípio, pelo menos, a troca entre o trabalho e o capital é plenamente equivalente e equitativa, comenta Zizek, fazendo a leitura de Marx, ao que acrescenta:

O problema é que a força de trabalho é uma mercadoria peculiar, cujo uso - o trabalho em si - produz uma certa mais-valia, e esse excedente que ultrapassa o valor da própria força de trabalho é apropriado pelo capitalista (ZIZEK, 1999, p. 307). 
O que está sendo questionado é que os equivalentes não são equivalentes como dissera Saussure (2004): uma palavra é o que a outra não é, não existem equivalentes na língua. Trata-se de uma estrutura de ficção que busca impor-se como "natural" e lógica. É o grande Outro da cultura produzindo o imaginário do sujeito. $\mathrm{O}$ "equivalente" é imaginário no sentido de cristalizar uma imagem do processo. O equivalente nunca é equivalente.

Nessa linha, instala-se um certo universal ideológico (o da troca equivalente e equitativa) e uma troca paradoxal particular (a da força de trabalho por seus salários) que, como um equivalente, funciona como a própria forma de exploração. A universalização da produção de mercadorias acarreta um sintoma, que funciona como sua negação interna. Marx (1983) afirma em O Capital, que esse elemento irracional é o proletariado, desrazão da própria razão, engendramento arbitrário do próprio capitalismo.

Pêcheux (1975) contribui com esta questão, referente ao estudo das práticas repressivas ideológicas, onde se esforça por compreender o processo de resistência-revolta-revolução:

Se, na história da humanidade, a revolta é contemporânea à extorsão do sobre-trabalho é porque a luta de classes é o motor dessa história. E se em outro plano, a revolta é contemporânea à linguagem, é porque sua própria possibilidade se sustenta na existência de uma divisão do sujeito, inscrita no simbólico (PÊCHEUX, 1997b, p. 302, o grifo é meu).

Se a revolta é contemporânea da linguagem como diz Pêcheux, (as obras que estou analisando também confirmam isso) e se $o$ inconsciente é mesmo efeito de linguagem e se o tratamento só é possível por meio da palavra, não seria a língua que determina o destino do sintoma? Esta é uma questão que Lacan se coloca em seu Seminário XXIII: O sinthoma (1975-1976). Trata-se de uma questão interessante para nós, analistas do discurso. Penso que enriqueceria a reflexão, o diálogo entre o sintoma e a sintaxe.

Leandro Ferreira (2000), ao abordar a sintaxe como o lugar de observação do discurso, trabalha a interface sintaxe/discurso. Conclui que é através da sintaxe como espaço de mediação entre a forma e o sentido que se dá o acesso à ordem da língua e à materialidade linguístico-histórica. É nesta zona que se situam os fatos linguísticos que forçam seus limites e desafiam as suas próprias regras.

Então, o que é possível dizer sobre o desejo que o sintoma concorda em inibir e transformar? Para isso, a língua precisa encontrar o equívoco, o melhor equívoco. Para tanto, a língua não pode ser um sistema dedutivo fechado, livre de lacunas, livre de excessos, mas capaz de rupturas. Isso acontece porque a lingua é um sistema sintático intrinsecamente passível de jogo, afirma a autora: 
E dentro desse espaço de jogo, as marcas significantes da língua são capazes de deslocamentos, de transgressões, de rearranjos. É isso que faz com que um determinado segmento possa ser ele mesmo ou outro através da metáfora, da homofonia, da homonímia, dos lapsos de língua, dos deslizamentos sêmicos, enfim, dos jogos de palavras e da dupla interpretação de efeitos discursivos (LEANDRO FERREIRA, 2000, p. 108). pontua:

Sobre esses recursos da língua e do inconsciente, Lacan

Está claro que todo ato falho é um discurso bem-sucedido, ou até formulado com graça e que no lapso é a mordaça que gira em torno da fala, e justamente pelo quadrante necessário para que um bom entendedor encontre ali sua meia-palavra (LACAN, 1998, p. 269, o grifo é meu).

Na obra apropriada da Publicidade/Propaganda e recriada pelo artista, é a viseira que gira sobre a imagem e mostra Outra-coisa e permite que o leitor encontre ali a sua meia-imagem, a imagem não-toda, capaz de ressignificá-lo momentaneamente. Neste desenfreamento do significante, encontramos o sujeito em formação discursiva heterogênea. As obras de arte que estão em análise me fazem pensar em produções novas que resultam dos efeitos subversivos da "condensação" e do "deslocamento" podem ser entendidas como emergências significantes do inconsciente que se estruturam em outra linguagem.

A sintaxe pode constituir uma forma de acesso importante para o analista do discurso e para o psicanalista, pois não há língua sem sintaxe e a organização das palavras não é jamais aleatória. O próprio Pêcheux "brinca" com seu estilo e reafirma seu esforço intelectual e afetivo para expressar um pensamento que perturba "a boa" ordem:

Parece-me, hoje, que Les Verités de La Palice roçaram essa questão dos estudos [das práticas repressivas ideológicas] de uma maneira estranhamente abortada, pelo viés de um sintoma recorrente que soava de maneira oca: estou querendo designar o prazer sistemático, compulsivo (e incompreensível para mim) que eu tinha em introduzir a maior quantidade possível de chistes - o que, pelo que sei, acabou por irritar mais de um leitor (PÊCHEUX, 1997b, p. 303).

Pêcheux assinala a dificuldade no campo teórico, político e social no tocante ao que pode ser dito e como deve ser dito. Algumas inibições resultam no abandono de uma função porque o exercício desta função produziria angústia. O eu renuncia a essas funções que estão ao seu alcance para evitar lançar mão de outras medidas de repressão e se poupa de um conflito com o id ou com o supereu. Freud em Inibição, sintoma e angústia (1925), salienta que este raciocínio permite compreender a inibição generalizada que caracteriza os estados de depressão e melancolia quando o sujeito se vê impedido no campo das ideias e/ou no campo dos afetos: 
No tocante às inibições, podemos então dizer, em conclusão, que são restrições das funções do ego que foram ou impostas como medida de precaução ou acarretadas como resultado de um empobrecimento de energia; e podemos ver sem dificuldade em que sentido uma inibição difere de um sintoma, porquanto um sintoma não pode mais ser descrito como um processo que ocorre dentro do ego ou que atua sobre ele (FREUD, 1976, p. 111).

Nesta citação Freud salienta a complexidade do sintoma em comparação com a inibição e a angústia. O sintoma se dá entre as instâncias psíquicas entre o eu e o id e entre o eu e o supereu, entre o eu e a realidade. Não se trata de um mero processo de recalcamento, mas implica outros processos, outros mecanismos, tais como, deslocamento e condensação.

Pêcheux refere que o seu sintoma era introduzir chistes para dizer o que precisava dizer, mesmo com grande resistência do meio acadêmico. Este é um ponto de afinidade entre Pêcheux e Freud. Freud iniciou a demonstração do inconsciente pelos sonhos que era uma experiência comum a todos. Os chistes de Pêcheux recebem função semelhante:

Era - percebo agora - o único meio de que eu dispunha para expressar, pela guinada do non-sens no chiste, o que o momento de uma descoberta tem fundamentalmente a ver com o desequilíbrio de uma certeza: o chiste é um indicador determinante pois, sendo estruturalmente análogo ao caráter de falta do lapso, acaba por representar, ao mesmo tempo, a forma de negociação máxima com a "linha de maior inclinação", o instante de uma vitória do pensamento no estado nascente, a figura mais apurada de seu surgimento. Isso reforça que o pensamento é fundamentalmente inconsciente ("isso [ça] pensa!"), a começar pelo pensamento teórico (e o "materialismo teórico de nosso tempo" não pode, sob risco grave, permanecer cego a esse respeito). Em outras palavras, o Witz representa um dos pontos visíveis em que o pensamento teórico encontra o inconsciente: o Witz apreende algo desse encontro, dando aparência de domesticar seus efeitos (PÊCHEUX, 1997b, p.303).

A citação acima pode ser um pouco longa, mas nada dela eu consegui retirar. Talvez por dizer tão bem da certeza da existência do inconsciente: Pêcheux narra o seu trajeto na Outra cena. Nesse diálogo, registro as palavras de Lacan:

A Outra cena, essa Outra-coisa, esse outro lugar, dimensão do Alhures presente para todos e vetado para cada um, "que sem que se pense nisso, e portanto, sem que qualquer um possa pensar estar pensando melhor que outro, isso pensa. Isso pensa um bocado mal, mas pensa com firmeza, pois foi nesses termos que ele (Freud) nos anunciou o inconsciente: pensamentos que, se suas leis não são de modo algum as mesmas de nossos pensamentos de todos os dias, nobres ou vulgares, são perfeitamente articulados" (LACAN, 1998, p. 554). 
É por circularem em uma Outra cena que Pêcheux, Freud e Marx pensam ser possível a mudança: a revolta e a revolução. Esta Outra cena que consiste na existência do inconsciente, tanto pode viabilizar o assujeitamento, quanto disponibilizar e construir artefatos de resistência.

Lacan em Escritos comenta que o sonho funciona como uma charada, no sentido de enigma. Afirma que o sonho tem a estrutura de uma frase: "Porém, é na versão do texto que o importante começa, o importante de que Freud nos diz está dado na elaboração do sonho, isto é, em sua retórica" (LACAN,1998, p. 267-268). É no discurso onírico que o sujeito modula com suas intenções ostentatórias ou as demonstrações dissimuladoras ou persuasivas, retaliadoras ou sedutoras através dos deslocamentos sintáticos e das condensações semânticas.

Para pensar a questão do assujeitamento, discuto o fetichismo da imagem - conceito trabalhado por Kehl (2004) - na tentativa de atualizar o que Marx chamou de ofetichismo da mercadoria, e que as obras de arte em análise apresentam e problematizam.

\section{$O$ fetichismo da imagem-mercadoria}

Segundo Marx, o fetichismo da mercadoria é uma "relação social definida entre os homens que assume aos olhos deles a forma fantasiosa de uma relação entre coisas" (MARX, 1983, p.77). Zizek (1996) discute essa questão do valor que uma certa mercadoria assume enquanto uma propriedade quase "natural" de outra coisa-mercadoria, que é o dinheiro. Dizemos que o valor de uma certa mercadoria é tal ou qual volume de dinheiro que ela solicita. Logo, o aspecto essencial do fetichismo da mercadoria não consiste na famosa substituição dos homens por coisas, mas num certo desconhecimento sobre a relação entre a estrutura e os elementos desta estrutura. Aquilo que é um efeito estrutural, um efeito da rede de relações entre os elementos, aparece como uma propriedade circunscrita de um dos elementos, como se essa propriedade também lhe pertencesse fora de sua relação com outros elementos, independentemente.

Esse efeito da rede de relações de sentido pode ocorrer entre coisas e entre as pessoas. A atribuição de valor de uma determinada mercadoria acontece quando esta é comparada a uma outra mercadoria. Da mesma forma, os homens necessitam do olhar uns dos outros para se reconhecerem. É a devolução do olhar de um outro ser humano que oferece a ideia de unidade para o sujeito, conforme a teoria do estádio do espelho de Lacan. É através do espelho do outro que o sujeito pode encontrar a sua identidade. De onde se pode conjeturar que o preço pago pela identidade é a alienação.

Marx dá seguimento a essa homologia: a outra mercadoria, $B$, só é um equivalente na medida em que a mercadoria A se relaciona com ela como sendo a forma-da-aparência de seu próprio 
valor, somente dentro dessa relação. Mas a aparência - e nisso reside o efeito de inversão que é característico do fetichismo -, a aparência é exatamente oposta: A parece relacionar-se com B como se, para $B$, ser um equivalente de $A$ não correspondesse a ser uma "determinação reflexa" de A - ou seja, como se B já fosse, em si mesmo, equivalente a A; a propriedade de "ser equivalente" parece pertencer-lhe até mesmo fora de sua relação com A, no mesmo nível de suas outras propriedades efetivas "naturais" que constituem seu valor de uso. A essas reflexões, mais uma vez, Marx acrescentou uma nota muito interessante:

Tais expressões das relações em geral, chamadas por Hegel de categorias reflexas, compõem uma classe muito curiosa. Por exemplo, um homem só é rei porque outros homens colocam-se numa relação de súditos com ele. E eles, ao contrário, imaginam ser súditos por ele ser rei (MARX, 1983, p. 63).

Esse raciocínio me parece muito próximo do conceito de formações imaginárias de Pêcheux (1997a) onde os sujeitos A e B designam lugares determinados na estrutura de uma formação social e esses lugares estão representados nos processos discursivos que se estabelecem. Pêcheux diz que a posição dos protagonistas do discurso intervém nas condições de produção do discurso. Nesse estudo, faço uma tentativa de transcrição das formações imaginárias para o esquema L de Lacan, seguindo a mesma topologia usada para ler a histeria e para ler a PP. Para tanto, proponho a seguinte superfície:

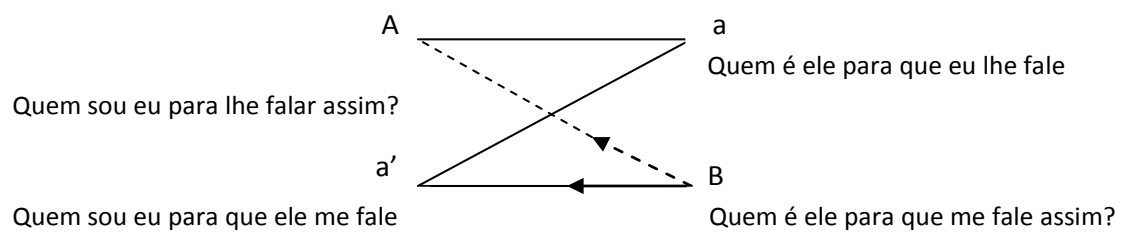

Fig. 6 - O Esquema L das Formações Imaginárias

Fonte: Campos, 2010

A questão que o analista do discurso coloca sobre a existência do sujeito é uma pergunta articulada sobre o lugar de onde fala o sujeito: "Quem sou eu nisso?" Que a questão de sua existência inunde o sujeito, suporte-o, invada-o ou até o dilacere por completo, é o que testemunham o psicanalista, o artista e o analista do discurso. As tensões, as suspensões e as fantasias com que eles se deparam é que lhes fazem empreender a análise e a arte. É sob a forma de elementos do discurso na história que essa questão do Outro, no Outro e para o Outro se articula. Pois é por esses fenômenos se ordenarem nas figuras desse discurso que eles têm fixidez de sintomas que são legíveis e que podem ser interpretados.

Portanto, "ser rei" é um efeito da rede de relações sociais entre um "rei" e seus "súditos". Os súditos imaginam que ser rei 
é uma propriedade natural da pessoa de um rei. E esse é o desconhecimento fetichista para os envolvidos nesse vínculo social. O rei só é rei porque os súditos são súditos e dispensam ao rei o tratamento de rei.

Zizek (1996) analisa duas modalidades de fetichismo: nas sociedades capitalistas e nas sociedades feudais. Nas sociedades capitalistas onde predomina a produção e a competição, as relações entre os homens não são fetichizadas. O que pode ser constatado é o fetichismo da mercadoria. As relações entre as pessoas "livres" para ser o que quiserem e para fazer o que quiserem, são relações egoístas onde cada um segue os seus interesses. O modelo dessas relações não segue o padrão de dominação-servidão, já que são pessoas que gozam de "liberdade" e "igualdade". Seu modelo é a troca mercantil, livre do fardo da veneração ao Senhor e da proteção do Senhor para com o escravo. As relações interpessoais são relações utilitárias, de interesses.

As duas formas de fetichismo, portanto, são incompatíveis: o fetichismo da mercadoria e o fetichismo do Senhor. O recuo do Senhor no capitalismo mostra-se apenas como um deslocamento, como se a desfetichização das relações "entre os homens" fosse paga com o fetichismo da mercadoria. O lugar do fetichismo apenas se desloca das relações intersubjetivas para as relações "entre coisas". As relações sociais decisivas, as de produção, deixam de ser imediatamente transparentes, como o eram as relações do Senhor com seus servos. Elas passam a se disfarçar sob a forma de relações sociais entre coisas, entre os produtos do trabalho.

Nesse raciocínio, considerando o mecanismo de deslocamento na produção das novas relações sociais, descobre-se o sintoma à maneira de Marx na passagem do feudalismo para o capitalismo: as relações de dominação e servidão continuam existindo, mas são recalcadas. Existe um mediador nas relações sociais capitalistas que disfarça as relações de dominação e servidão - que é a mercadoria.

A imensa e variada oferta de mercadorias e a onipresença dos apelos da publicidade, emitidas a partir desta encarnação do grande Outro, chamado ideologia capitalista, e que tem na mídia de massa seu porta-voz - produzem uma ilusão. A ilusão de que nada foi perdido e que temos ao alcance da mão uma quantidade de objetos inusitados para simular o objeto perdido do nosso mais-gozar, o objeto a (BUCCI; KEHL, 2004, p. 75).

Com efeito, o que a presença do objeto mercadoria procura subtrair é a função da palavra e da linguagem. A mercadoria liga-se ao modelo do que Lacan denominou de lathouse - expressão intrigante, que beira o non-sens, introduzida em $O$ avesso da psicanálise (1969-1970). Ele nos diz que "o mundo está cada vez mais povoado de lathouses", que não é o Outro, não é o ente, não é bem o ser, está entre os dois: 
E quanto aos pequenos objetos $a$ que vão encontrar ao sair, no pavimento de todas as esquinas atrás de todas as vitrines, na proliferação desses objetos feitos para causar o desejo de vocês, na medida em que agora é a ciência que governa, pensem neles como latusas (LACAN, 1992, p.172).

A palavra lathouse é o aoristo do verbo grego Lanthanô que quer dizer estar escondido sem saber. Aquilo que já esteve presente e agora está ausente. A lathouse remete para a questão da perda na qual se origina qualquer objeto com dimensões humanizadas. Um objeto no qual a falta permanece escondida. A lathouse, que para Lacan lembra e rima com venthouse, ventosa: aquilo que não inspira, mas aspira o desejo. Neste "turbilhão infernal do laço social dominante", como ele chama o discurso capitalista, talvez seja possível estabelecer uma aproximação com o sintoma histérico que trata de substituir o Outro nesta função do desejo. O desejo na histeria e o desejo no capitalismo é o desejo de desejar.

Para Rancière (2006, p.14), a singularidade da arte se aproxima à potência do Unheimlich freudiano. A virtude da arte consiste em ser testemunha do "desastre totalitário, consequência última do sonho de uma humanidade dona de seu próprio destino". A arte é o observatório da dependência em relação à potência do Outro, da miséria e do horror que desconstrói o projeto de autonomia e de unidade do sujeito. A arte opera a revelação traumática do mal-estar na cultura.

As obras em análise neste artigo são imagens mediadoras entre o sujeito e a mercadoria, onde o artista busca desestabilizar a relação imaginária que a publicidade/propaganda esforça-se por reproduzir de estímulo ao consumo. A forma de apresentação do inconsciente, da arte e da ideologia é a estética. Enquanto o inconsciente e a ideologia funcionam por representações, a arte trata da re-apresentação. De mostrar de novo, de mostrar mais uma vez o que não pode ser visto na diferença.

\begin{abstract}
This paper is an attempt to make a provisional reading of the contemporary society, and the condition of the subject's resistance. This is the subject and merchandise captured by advertising, where the artist makes a complaint. Search an approximation between the fields of art, psychoanalysis and discourse analysis. This proposes a discussion through the scheme L of Lacan to think the imaginary relationship of the subject with advertising.
\end{abstract}

Keywords: Image; Resistance; Subject. 


\section{REFERÊNCIAS}

CAMPOS, Luciene J. Imagens à Deriva: Interlocuções entre a arte, psicanálise e a análise do discurso. Tese de doutorado não-publicada, Programa de Pós-Graduação em Letras, Universidade Federal do Rio Grande do Sul. Porto Alegre, Brasil, 2010.

BUCCI, Eugênio; KEHL, Maria Rita. Videologias: ensaio sobre a televisão. São Paulo: Boitempo, 2004 (Estado de sítio).

DEBORD, Guy. A sociedade do espetáculo. Rio de Janeiro: Contraponto, 1997.

FOUCAULT, Michel. O nascimento da clínica. 2. ed. Rio de Janeiro: Forense Universitária, 2006.

GOLDGRUB, Carlos. Outdoor's: São Paulo um retrato urbano. São Paulo: Goldgrub, 2012.

FREUD, Sigmund. Inibição, sintoma e angústia (1925). In: Obras Completas. Edição Standard Brasileira. Rio de Janeiro, Imago, 1976. LACAN, Jacques. O seminário, livro 17: o avesso da psicanálise (1969-1970) texto estabelecido por Jacques Alain-Miller. Tradução Ary Roitman. (Campo Freudiano no Brasil). Rio de Janeiro: Jorge Zahar, 1992.

LACAN, Jacques. Seminário XXIII: O sinthoma (1975-1976) (Campo Freudiano no Brasil). Rio de Janeiro: Jorge Zahar.

LACAN, Jacques. Escritos (Campo Freudiano no Brasil). Rio de Janeiro: Jorge Zahar, 1998.

LEANDRO FERREIRA, M. Cristina. Da ambiguidade ao equívoco: a resistência da língua nos limites da sintaxe e do discurso. Porto Alegre: Universidade/UFRGS, 2000.

MARX, Karl. O Capital. São Paulo: Abril Cultural, 1983.

PÊCHEUX, Michel. Análise automática do discurso (AAD-1969) In: GADET, François; HAK, Tony. Por uma análise automática do discurso: uma introdução à obra de Michel Pêcheux. Campinas: UNICAMP, 1997a.

PÊCHEUX, Michel. Semântica e discurso: uma crítica à afirmação do óbvio (1975). Tradução Eni Orlandi [et al.]. 3. ed. Campinas: UNICAMP, 1997b.

PÊCHEUX, Michel; FUCHS, Cathérine. A propósito da análise automática do discurso: atualização e perspectivas (1975) In: GADET, François; HAK, Tony. Por uma análise automática do discurso: uma introdução à obra de Michel Pêcheux. Campinas: UNICAMP, 1997. RANCIÈRE, Jacques. El inconsciente estético. Serie Pensamiento Contemporáneo. Buenos Aires: Del Estante, 2006.

SAUSSURE, Ferdinand. Curso de Linguística Geral. São Paulo: Cultrix, 2004.

ZIZEK, Slavoj (Org.). Um mapa da ideologia. Rio de Janeiro: Contraponto, 1996. 